\title{
Pharmacological pain management in patients with chronic kidney disease
}

\author{
László Irsay ${ }^{1}$, Alexandra Checicheș ${ }^{2}$, Dănuț Perja ${ }^{2}$, Ileana Monica Borda ${ }^{1}$, Gabriela Dogaru ${ }^{1}$, \\ Ioan Onac ${ }^{1}$, Rodica Ungur ${ }^{1}$, Viorela Ciortea ${ }^{1}$
}

Corresponding author: László Irsay, E-mail: irsaylaszlo@gmail.com

\section{1. "Iuliu Hatieganu" University of Medicine and Pharmacy Cluj-Napoca, Romania}

2. Clinical Rehabilitation Hospital Clui-Napoca. Romania

\begin{abstract}
Chronic kidney disease (CKD) is one of the most frequently seen comorbidities in patients suffering from musculoskeletal conditions; it is defined by a glomerular filtration rate (GFR) under $60 \mathrm{ml} / \mathrm{min} / 1.73 \mathrm{~m} 2$. The following paper focuses on providing a dosage adjustment guideline depending on how advanced renal impairment is. A literature search was carried out using the following items: pharmacokinetics, side effects, drug interactions and dosage, pain medication and antirheumatic drugs in renal failure.

The use of non-steroidal anti-inflammatory drugs is inadvisable for a GFR $<30 \mathrm{ml} / \mathrm{min}$ as they all pose the risk of inducing acute renal damage, as well as worsening of the underlying chronic renal disease. Non-steroidal antiinflammatory drugs (NSAIDs) should be avoided due to the possibility of kidney disease progression. Paracetamol is an analgesic often chosen in this category of patients. As far as opioid analgesics are concerned, methadone is the only one that can be used without dosage adjustment. Physiotherapy remains a good and safe option for treatment in patients with musculoskeletal complaints.
\end{abstract}

The use of analgesics in patients with CKD continues to be a challenge, as more research is needed.

Key words: chronic kidney disease, pain, medication, antirheumatic drug,

\section{Introduction}

Patients with chronic kidney disease (CKD) have a large number of comorbidities that modulate the response to pain. Chronic pain is common in CKD and affects $50 \%$ of hemodialysis patients. From this category, $82 \%$ show moderate to severe pain.

One study reported up to $47 \%$ chronic pain in CKD stage 5 patients (1).

The etiology of pain can be iatrogenic in some procedures, but is more often due to comorbidities such as arterial disease or diabetes. The most frequent cause of pain is represented by musculoskeletal disorders (63\%), of which osteoarthritis is the most common, followed by peripheral vascular disease, bone diseases (renal osteodystrophy, osteoporosis with vertebral fractures), arthritis, and peripheral neuropathy (2).

CKD affects the renal excretion mechanism of drugs and the pharmacokinetic processes involved in their distribution (e.g., absorption, clearance, extrarenal distribution, metabolism). Improper dosage adjustment of medications is common in patients with renal impairment and may cause frequent adverse effects or poor therapeutic outcomes.

The general principles of assessment, pain management and analgesia should be prescribed taking into account the WHO recommendations for pain management in these patients, with careful and frequent monitoring of possible side effects of the drug itself or its metabolite accumulation data. Clinical management should be performed by a multidisciplinary team that includes a clinical nephrologist and a pharmacist (3).

The K/DOQI Advisory Board has divided the progression of CKD into five stages (see Table 1).

Table 1. Stages of CKD

\begin{tabular}{|c|c|c|c|}
\hline Stages & $\begin{array}{c}\text { CKD } \\
\text { Stage }\end{array}$ & $\begin{array}{c}\text { Glomerular } \\
\text { filtration rate } \\
\mathrm{ml} / \mathrm{min} / 1.73 \mathrm{~m}^{2}\end{array}$ & $\begin{array}{c}\text { Creatinine clearance } \\
(\mathrm{CrCl}) \\
\mathrm{ml} / \mathrm{min}\end{array}$ \\
\hline $\begin{array}{c}\text { Normal kidney } \\
\text { function }\end{array}$ & 1 & $>90$ & 120 \\
\hline $\begin{array}{c}\text { Mild decreased } \\
\text { function }\end{array}$ & 2 & $60-89$ & $20-50$ \\
\hline Moderate & 3 & $30-59$ & $10-20$ \\
\hline Severe & 4 & $15-29$ & $<10$ \\
\hline $\begin{array}{c}\text { End-stage } \\
\text { renal disease }\end{array}$ & 5 & $<15$ & $<10$ \\
\hline
\end{tabular}


Knowing the adverse drug reactions in patients with CKD is particularly important because only in this way can further damage of residual kidney function be prevented $(4,5,6)$.

For patients with significant glomerular filtration rate (GFR) reductions, dose adjustment and avoidance of certain analgesics is necessary because of a change in the pharmacokinetics and pharmacodynamics of several analgesics or their metabolites. Patients with CKD have an increased risk of adverse effects due to several aspects such as: comorbidities, increased susceptibility to medication, reduction of muscle/body mass, reduced therapeutic and toxic dose, and accumulation of medication due to low excretion. These pharmacokinetic characteristics and pharmacodynamic changes depend on the pharmacological agent itself, the stage of renal insufficiency and whether the patient undergoes dialysis $(7,8)$.

An increased number of patients with CKD are elderly, and this may further enhance the sensitivity of these patients to analgesics.

The quality of life of patients with CKD is impaired both by the underlying disease and the presence of pain $(9,10)$.

Monitoring of renal function is required in all situations where the drug that needs to be administered has renal toxic effects or is renally excreted.

In most cases of acute and chronic pain in CKD patients, physiotherapy should be performed as a non-pharmacological alternative.

In what follows, the authors aim to review most of the drugs used in pain management and their restrictions in patients with $\mathrm{CKD}$, using their own experience.

\section{ANALGESICS}

\section{STAGE I ANALGESICS}

\section{Acetaminophen}

It is considered the first option in the treatment of pain. It should be kept in mind that long-term use itself may cause nephrotoxicity. Many authors do not consider dose adjustment with a GFR $=50$ $\mathrm{ml} / \mathrm{min}$ (maximum dose $4 \mathrm{~g} /$ day), but frequent comorbidities in CKD patients require caution. A GFR below $50 \mathrm{ml} / \mathrm{min}$ requires dose reduction $(11,12)$.

\section{Non-steroidal anti-inflammatory drugs (NSAIDs)}

They should be avoided even in minor/mild renal insufficiency, but in certain situations they are accepted in stage $1 \mathrm{CKD}$. Prostaglandins mediate the compensatory vasodilation of related arterioles that vascularize the glomerulus to maintain GFR states of hypovolemia and hypotension (13).

NSAIDs lead to the renal exhaustion of prostaglandins with vasodilatory effects and allow for uncontrolled vasoconstriction. From a clinical point of view, these mechanisms can have catastrophic and unpredictable effects by diminishing blood flow. Generally, the triad NSAIDs, diuretics and angiotensin-converting enzyme (ACE) inhibitors can severely affect GFR and renal function. However, in most cases, the effect may be transient, without clear evidence of long-term impaired renal function. The risk of using NSAIDs in this patient group should be considered in relation to benefit. If NSAIDs are to be used, they should be limited to the shortest possible duration and renal function should be monitored closely. NSAIDs should be avoided in patients with additional risk factors that may affect kidney function, such as older age, diabetes mellitus, and the use of ACE inhibitors. One of the limited indications of NSAID administration is gout attack $(14,15,11,4)$.

Topical use of NSAIDs is recommended as an alternative to general administration.

\section{STAGE II ANALGESICS}

Codeine. Half-life is significantly prolonged in CKD. Accumulation of active metabolites may lead to severe adverse reactions (e.g., respiratory arrest, narcolepsy and severe hypotension).

In mild $\mathrm{CKD}$, the normal daily dose is permitted with function monitoring. In moderate CKD, a 75\% reduction of the normal dose is required, and in severe $\mathrm{CKD}, 50 \%$ of the normal dose is needed (16).

Tramadol. The active metabolite is renally excreted. 
In mild CKD - 50-100 mg in a single dose can be administered, moderate impairment increases the dose interval - 50-100 mg divided into 2 doses, and in severe damage it should be avoided.

In end-stage renal disease, at $\mathrm{CrCl}<30 \mathrm{ml} / \mathrm{min}, 50$ $100 \mathrm{mg}$ doses every 12 hours (maximum: 200 $\mathrm{mg}$ /day). Retard forms of tramadol will not be prescribed in patients with $\mathrm{CrCl}<30 \mathrm{ml} /$ minute (16).

\section{STAGE III ANALGESICS}

\section{Morphine}

Morphine is metabolized by the liver; $5-10 \%$ is excreted unchanged by the kidney. The hepatic metabolites of morphine, such as morphine-6glucuronide (M6G) and morphine-3-glucuronide, are associated with hyperalgesia and neurotoxicity when accumulated in patients with severe renal impairment. At a GFR of $50 \mathrm{ml} / \mathrm{min}$, the dose is reduced to less than $50 \%$, and morphine is avoided in patients with a GFR below $50 \mathrm{ml} / \mathrm{min}$.

Morphine is removed by dialysis $(4,2)$.

Oxycodone. It is metabolized in the liver and less than $10 \%$ is renally excreted. It should be used with great caution in moderate renal impairment; a second-line agent should be considered in CKD. Dosage adjustment is recommended (data is poor) according to the following schedule:

A GFR of $20-50 \mathrm{ml} / \mathrm{min}$ does not require dose adjustment; at a GFR $<20 \mathrm{ml} / \mathrm{min}$ - to be avoided.

There is no data on the effect of dialysis on oxycodone and its breakdown products (2).

\section{Fentanyl}

It has a safe pharmacological profile in patients with CKD. Hepatic metabolism is reduced, less than $10 \%$ is renally excreted. Dosage adjustment is recommended according to the following schedule:

A GFR of $20-50 \mathrm{ml} / \mathrm{min}$ - normal dose. For a GFR less than $20 \mathrm{ml} / \mathrm{min}$, it is recommended to reduce the dose due to the phenomenon of serum accumulation and increased risk of toxic reactions $(11,8)$.

\section{Methadone}

Methadone is fecally excreted, with no active metabolites. It is not removed by dialysis. No dose reduction is needed up to a GFR of $10 \mathrm{ml} / \mathrm{min}$ (17).

\section{ADJUVANT ANALGESICS}

This category consists of drugs that can be administered in association with other medications, or in certain situations they can be administered individually.

\section{Gabapentin}

Gabapentin is excreted unchanged in the urine. In our practice we used the following dose adjustment (see Table 2):

GFR 30-50 $\mathrm{ml} / \mathrm{min}-\max 300-700 \mathrm{mg}$ in two divided doses;

GFR $10-20 \mathrm{ml} / \mathrm{min}$ - max $300 \mathrm{mg}$ in a single dose;

GFR $<10 \mathrm{ml} / \mathrm{min}$ - $\max 300 \mathrm{mg}$ every other day.

Due to other side effects such as dizziness, sleepiness, gabapentin can be difficult to tolerate in elderly patients (17).

Table 2. Gabapentin - dosage

\begin{tabular}{|c|c|}
\hline $\begin{array}{c}\text { Creatinine clearance } \\
(\mathrm{mg} / \mathrm{ml})\end{array}$ & $\begin{array}{c}\text { Daily dose } \\
(\mathrm{mg} / \mathrm{day})\end{array}$ \\
\hline$\geq 80$ & $900-3600$ \\
\hline $50-79$ & $600-1800$ \\
\hline $30-49$ & $300-900$ \\
\hline $15-29$ & $150-600$ \\
\hline$<15$ & $150-300$ \\
\hline
\end{tabular}

\section{Pregabalin}

Dose adjustment is recommended according to the following schedule (see Table 3):

Table 3. Pregabalin - dosage (18)

\begin{tabular}{|c|c|c|c|c|c|}
\hline $\begin{array}{c}\text { Creatinine } \\
\text { clearance } \\
(\mathrm{ml} / \mathrm{min})\end{array}$ & \multicolumn{3}{|c|}{$\begin{array}{c}\text { Total pregabalin daily dose } \\
\text { (mg/day) }\end{array}$} & Dose regimen \\
\hline$\geq 60$ & 150 & 300 & 450 & 600 & $\begin{array}{c}\text { TID = three } \\
\text { divided doses or } \\
\text { BID = two } \\
\text { divided doses }\end{array}$ \\
\hline $30-60$ & 75 & 150 & 225 & 300 & TID or BID \\
\hline $15-30$ & $25-$ & 75 & $100-$ & 150 & BID or one dose \\
& 50 & & 150 & & One dose \\
\hline$<15$ & 25 & $25-$ & $50-$ & 75 & 75 \\
\hline
\end{tabular}

3. Dexamethasone. It does not require dose adjustment, but attention should be paid to urea retention.

4. Amitriptyline. A tricyclic antidepressant with no renal excretion, it can be used in renal impairment at doses of 10-25 mg/day up to $75 \mathrm{mg} /$ day, depending on the patient's response $(19,20)$.

\section{OTHER MEDICATIONS}

\section{Colchicine}


In mild ( $\mathrm{CrCl}: 50-80 \mathrm{ml} / \mathrm{min}$ ) and moderate $\mathrm{CKD}$ (CrCl: $30-50 \mathrm{ml} / \mathrm{min}$ ), dose adjustment is not required, but patients should be carefully monitored for possible side effects.

In severe $\mathrm{CKD} \quad(\mathrm{CrCl}<30 \mathrm{ml} / \mathrm{min})$ : no dose adjustment is required, but a treatment course should not be repeated more than once every two weeks. For patients requiring repeated treatment, alternative therapy should be considered. Colchicine is not eliminated by hemodialysis, so there is a risk of myo/neurotoxicity (21).

\section{Allopurinol}

Dosage adjustment in renal impairment is required depending on creatinine clearance $(\mathrm{CrCl})$ :

Parenteral doses:

$\mathrm{CrCl}$ less than $3 \mathrm{ml} / \mathrm{min}$ : $100 \mathrm{mg} /$ day with prolonged dosing interval;

$\mathrm{CrCl}: 3-10 \mathrm{ml} / \mathrm{min}: 100 \mathrm{mg} /$ day;

CrCl: 10-20 ml/min: $200 \mathrm{mg} /$ day.

Oral doses:

$\mathrm{CrCl}$ less than $10 \mathrm{ml} / \mathrm{min}: 100 \mathrm{mg}, 3$ times/week;

$\mathrm{CrCl}: 10 \mathrm{ml} / \mathrm{min}$ : $100 \mathrm{mg}$ on alternate days;

$\mathrm{CrCl}: 20 \mathrm{ml} / \mathrm{min}$ : $100 \mathrm{mg}$ once/day;

$\mathrm{CrCl}: 40 \mathrm{ml} / \mathrm{min}: 150 \mathrm{mg}$ once/day;

$\mathrm{CrCl}: 60 \mathrm{ml} / \mathrm{min}$ : $200 \mathrm{mg}$ once/day.

In hemodialysis patients, administration of allopurinol is unnecessary because uric acid is eliminated by hemodialysis. Switching to febuxostat is recommended in every case of CKD with hyperuricemia. In special cases where allopurinol is recommended, the dose administered at the end of the hemodialysis session should not exceed 200 $\mathrm{mg} / \mathrm{session}(21)$.

\section{Febuxostat}

No dose adjustment is necessary in patients with mild or moderate CKD. There are no consistent data for GFR below $30 \mathrm{ml} / \mathrm{min}$. The effects of delaying renal impairment in patients with CKD have been demonstrated in several studies, and not only in those with hyperuricemia or gout. In clinical trials, it has been demonstrated to reduce uremia faster than allopurinol $(22,23,24)$.

\section{Conclusions}

Pain management in patients with CKD is challenging because of the difficulty in choosing between different drugs due to direct renal toxicity or comorbidity. Choosing a medicine should be done with caution using clinical judgment to avoid further deterioration in renal function. Knowing the pharmacokinetics of analgesic drugs helps the clinician predict renal tolerance and response to treatment.

\section{Conflicts of interest}

The authors of this paper state that there are no conflicts of interest regarding the study methodology, results and conclusions drawn.

\section{References}

1. Murtagh FE, Eddington-Hall J, Higginson IJ. The prevalence of symptoms in end-stage renal disease: A systematic review. Adv Chronic Kidney Dis 2007; 14:82-99

2. Nagar VR, Birthi P, Salles S, Sloan PA. Opioid Use in Chronic Pain Patients with Chronic Kidney Disease: A Systematic Review. Pain Med. 2017 Aug 1;18(8):1416-1449

3. Zyga S, Alikari V, Sachlas A, Stathoulis J, Aroni A, Theofilou P, Panoutsopoulos G. Management of Pain and Quality of Life in Patients with Chronic Kidney Disease Undergoing Hemodialysis. Pain Manag Nurs. 2015 Oct;16(5):712-20

4. Tawfic QA, Bellingham G. Postoperative pain management in patients with chronic kidney disease. J Anaesthesiol Clin Pharmacol. 2015 Jan-Mar; 31(1): 6-13.

5. Niscola P, Scaramucci L, Vischini G, Giovannini M, Ferrannini M, Massa P, Tatangelo P, Galletti M, Palumbo R. The use of major analgesics in patients with renal dysfunction. 2010 Jun;11(6):752-8

6. Farrell A, Rich A. Analgesic use in patients with renal failure. Eur J.Pall.Care 2000; 7(6):201-205

7. Williams A, Manias E. A structured literature review of pain assessment and management of patients with chronic kidney disease. J Clin Nurs. 2008;17:69-81.

8. Davison SN. Pain in hemodialysis patients: Prevalence, cause, severity, and management. Am J Kidney Dis. 2003;42:1239-47

9. Levey AS, Coresh J, Balk E, Kausz AT, Levin A, Steffes MW, et al. National Kidney Foundation 
practice guidelines for chronic kidney disease: Evaluation, classification, and stratification. Ann Intern Med. 2003;139:137-47

10. Nayak-Rao S. Achieving effective pain relief in patients with chronic kidney disease: A review of analgesics in renal failure. J Nephrol. 2011;24:3540.

11. Kurella M, Bennett WM, Chertow GM. Analgesia in patients with ESRD: A review of available evidence. Am J Kidney Dis. 2003;42:21728.

12. Toussaint $\mathrm{K}$, Yang XC, Zielinski MA, Reigle KL, Sacavage SD, Nagar S, et al. What do we (not) know about how paracetamol (acetaminophen) works? J Clin Pharm Ther. 2010;35:617-38

13. Lee A, Cooper MG, Craig JC, Knight JF, Keneally JP. Effects of nonsteroidal antiinflammatory drugs on postoperative renal function in adults with normal renal function. Cochrane Database Syst Rev. 2007;2:CD002765.

14. Huerta C, Castellsague J, Varas-Lorenzo C, García Rodríguez LA. Nonsteroidal antiinflammatory drugs and risk of ARF in the general population. Am J Kidney Dis. 2005;45:531-9.

15. Stürmer T, Elseviers MM, De Broe ME. Nonsteroidal anti-inflammatory drugs and the kidney. Curr Opin Nephrol Hypertens. 2001;10:1613.

16. Pham PC, Khaing K, Sievers TM, Pham PM, Miller JM, Pham SV, Pham PA, Pham PT. 2017 update on pain management in patients with chronic kidney disease. Clin Kidney J. 2017 Oct;10(5):688697

17. O'Connor NR, Corcoran AM. End-stage renal disease: symptom management and advance care planning. Am Fam Physician. 2012 Apr 1;85(7):705-10.

18.http://labeling.pfizer.com/showlabeling.aspx?id=

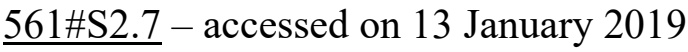

19. Cohen LM, Moss AH, Weisbord SD, Germain MJ. Renal palliative care. J Palliat Med. 2006 Aug;9(4):977-92

20. Kidney Disease: Improving Global Outcomes (KDIGO) CKD Work Group. KDIGO 2012 Clinical Practice Guideline for the Evaluation and Management of Chronic Kidney Disease. Kidney inter., Suppl. 2013; 3: 1-150

21. Vargas-Santos AB, Neogi T. Management of Gout and Hyperuricemia in CKD. Am J Kidney Dis. 2017 Sep;70(3):422-439

22. Pisano A, Cernaro V, Gembillo G, D'Arrigo G, Buemi M, Bolignano D. Xanthine Oxidase Inhibitors for Improving Renal Function in Chronic Kidney Disease Patients: An Updated Systematic Review and Meta-Analysis. Int J Mol Sci. 2017 Oct $31 ; 18(11)$

23. Sezai A, Soma M, Nakata K, Osaka S, Ishii Y, Yaoita H, Hata H, Shiono M. Comparison of febuxostat and allopurinol for hyperuricemia in cardiac surgery patients with chronic kidney disease (NU-FLASH trial for CKD). J Cardiol. 2015 Oct;66(4):298-303

24. Yamaguchi A, Harada M, Yamada Y, Hashimoto K, Kamijo Y. Identification of chronic kidney disease patient characteristics influencing the renoprotective effects of febuxostat therapy: a retrospective follow-up study. BMC Nephrol. 2017 May 18;18(1):162. 